\title{
Habitat Fragmentation, Connectivity Conservation and Related Key-Concepts: Temporal Trends in Their Recurrences on Web of Science (1960-2020)
}

\author{
Corrado Battisti ${ }^{1, *(\mathbb{D}}$, Luca Gallitelli ${ }^{2}{ }^{\mathbb{D}}$, Massimiliano Scalici ${ }^{2}$ and Francesco M. Angelici ${ }^{3}$ \\ 1 Torre Flavia Wetland' LTER (Long Term Ecological Research) Station, Protected Areas Service, \\ Città Metropolitana di Roma Capitale, 00148 Rome, Italy \\ 2 Department of Sciences, University Roma Tre, Viale G. Marconi 446, 00146 Rome, Italy; \\ luca.gallitelli@uniroma3.it (L.G.); massimiliano.scalici@uniroma3.it (M.S.) \\ 3 National Center for Wildlife, Al Imam Faisal Ibn Turki Ibn Abdullah, Ulaishah, Riyadh 12746, Saudi Arabia; \\ francesco.angelici@un.org \\ * Correspondence: c.battisti@cittametropolitanaroma.it
}

\section{check for}

updates

Citation: Battisti, C.; Gallitelli, L.;

Scalici, M.; Angelici, F.M. Habitat

Fragmentation, Connectivity

Conservation and Related

Key-Concepts: Temporal Trends in

Their Recurrences on Web of Science

(1960-2020). Land 2022, 11, 230.

https://doi.org/10.3390/

land 11020230

Academic Editor:

Ioannis N. Vogiatzakis

Received: 26 December 2021

Accepted: 1 February 2022

Published: 3 February 2022

Publisher's Note: MDPI stays neutral with regard to jurisdictional claims in published maps and institutional affiliations.

Copyright: (c) 2022 by the authors. Licensee MDPI, Basel, Switzerland. This article is an open access article distributed under the terms and conditions of the Creative Commons Attribution (CC BY) license (https:// creativecommons.org/licenses/by/ $4.0 /)$.

\begin{abstract}
In this work, we analyzed the temporal trends of nine selected key terms used in the habitat fragmentation arena, quantifying their number (and frequency) of recurrence on Web of Science from 1960 to 2020. The most used key (focal) terms ("stepping stones", "habitat corridors", "landscape connectivity"), showed a progressive increase from 1981 to 2020, with "landscape connectivity" showing the highest increase in frequency in the last decade (2011-2020). Among the key secondary terms (recurring < 5\%), although "corridors", "continuity", and "contiguity" showed a slight growth over the decades, "connectivity conservation" showed the most significant increase. This last landscape-related term recently replaced other local-scale concepts (as "stepping stones" and "corridors") as a consequence of a change of perspective. Conversely, "ecological network planning", used in landscape planning and less in conservation biology, showed a comparable fewer recurrence. This gap in recurrences could be due to a bias in our research approach, as Web of Science is a search engine that does not intercept grey literature (as plans and reports) drawn up by Public Agencies which rarely appears in scientific journals.
\end{abstract}

Keywords: conservation biology; connectivity conservation; ecological network planning; landscape planning; wildlife management

\section{Introduction}

The awareness that habitat fragmentation (hereafter, HF, i.e., the breaking up of larger areas of natural land cover into smaller, more isolated patches, independent of a change in the total area of natural land cover) is a process disrupting the structure and dynamics of species and ecosystems at different scales that had emerged already in the 1950s with the seminal book "The Man's Role" [1]. Since the 1970s, the evidence that this landscapescale process may improve the insularization of remnant ecosystems led to the use of theories and approaches of insular biogeography, applying them to the mainland [2]. In the 1980s, Conservation Biology established itself as a scientific discipline [3] and HF was included among the anthropogenic threats capable of irreversibly impacting environmental components, for example, by initiating large-scale extinction processes of species with cascade effects at a higher (e.g., community) level (e.g., [4-7]). The first studies focused mainly on the response of species to HF in both temperate (e.g., [8]) and tropical (e.g., [9]) landscapes and on the need to mitigate the effects of this process. In this phase, specific concepts have been introduced, for example, the key term "corridor" (e.g., [10,11]). In this decade, a large amount of research highlighted HF as a process with species-specific effects at different spatial/temporal scales and hierarchical levels (form individuals, to populations, to communities and ecosystems processes) [8]. 
This conservation topic exploded in the 1990s when brainstorming started between researchers and planners led to the definition of operational defragmentation strategies aimed at mitigating the effects of this process: in this regard, new concepts have been developed such as "landscape connectivity", i.e., "the degree to which the landscape facilitates or impedes movement of individuals or propagules among resource patches", demonstrating that minimizing the effects of isolation by enhancing landscape connectivity is one way to counter the adverse effects of HF (e.g., [12]). All these new key terms became part of the topic-specific language in many disciplines (landscape ecology: [13]; landscape and urban planning: [14]; wildlife management: [15]; conservation biology: [16]).

However, the use of these key terms in different disciplines, often not clearly defined, lead to misunderstanding and linguistic and semantic uncertainty. To overcome this, in 1999 the IUCN produced a monographic work on landscape linkages [17] which contained a review of the new key concepts that in recent years were emerging in the HF arena, to standardize the new language. Therefore, following a problem-solving approach [18], (i) the conservation problem (due to HF) was identified, (ii) solutions were developed, and (iii) planning and project strategies started. In this way, the new key concepts of "stepping stones", "habitat corridors", "landscape connectivity", "landscape continuity", "landscape contiguity", "habitat linkages", "landscape linkages" were specified and entered in the languages of landscape planning and conservation biology. In particular, some terms (such as "stepping stones", "habitat corridors", "habitat linkages") focused attention on single habitat patches in the landscape (local scale), and others (as "landscape connectivity", "landscape continuity" and "landscape contiguity") focused on processes at the landscape scale. In this regard, in the 1990s, conservation strategies aimed to mitigate the HF should focus not on the patch scale but at the landscape level [19].

Furthermore, two key concepts emerged in the 1990s linked to defragmentation strategies (i.e., "connectivity conservation" and "ecological network planning") belonging to two very different sectors: the first belonging to the arena of conservation biology, the second belonging to the landscape and urban planning. While the first relates to the strictly biological arena (producing scientific literature, registered on search engines), the second concerns an urban planning disciplinary arena that prefers the drafting of technical plans and reports for Public Agencies with scant use of the scientific literature.

This gap between conservation researchers and landscape planners has been highlighted [20] also in the HF arena [21].

In this work, we aimed at describing the temporal trends of the different terms used in the HF arena, quantifying their number (and frequency) of recurrences to obtain data on use in the decades from 1960 to 2020 . In particular, we hypothesize (i) use of the key terms related to the larger landscape scale in recent years due to a change in perspective: from patch/corridor in the 1980s to the landscape scale in the 1990s (e.g., [22]), and (ii) more frequent recurrence of the term "connectivity conservation" rather than "ecological network planning" in the scientific research web search engine, given that the use of these terms pertains to different disciplinary arenas (scientific/biological vs. urban planning ones, respectively; see [23]). We believe that knowing the temporal trends of the different terms used in the HF-related disciplines can contribute to the search for terminological standards, favoring the disciplinary exchange between the conservation vs. planning arenas. Although analogous reviews in this regard are available (e.g., [24]), to our knowledge this is the first review comparing the use of different HF-related terms on such a long time range.

\section{Materials and Methods}

First, we selected a number of key terms ("stepping stones", "habitat corridors", "landscape connectivity", "landscape continuity", "landscape contiguity", "habitat linkages", "landscape linkages", "connectivity conservation", "ecological network planning"), largely used in HF disciplinary arena. We defined each one of these key terms as follows: 
- "stepping stones": One or more separate patches of habitat in the intervening space between ecological isolates, that provide resources and refuge that assist animals to move through the landscape [17];

- "habitat corridors": A linear strip of habitat that provides a continuous (or near continuous) pathway between two patches. This term has no implications about its relative use by animals [10,11,17];

- "landscape connectivity": the process aimed to counter the adverse effects of HF; landscape connectivity depends on the availability and arrangement of suitable habitats $[12,13]$;

- "landscape continuity": the ability to allow the dynamics of species and individuals: two habitat patches are continuous if they allow the dispersion of individuals or propagules between patches [17];

- "landscape contiguity": the physical component of the landscape connectivity; two habitat patches are contiguous if they are adjacent to each other [17];

- "habitat linkages": an arrangement of habitats (not necessarily linear or continuous) at a local scale that enhances the movement of animals and plant propagules [17];

- "landscape linkages": an arrangement of habitats (not necessarily linear or continuous) at the landscape scale that enhances the movement of animals and plant propagules [17];

- "connectivity conservation": the action of individuals, communities, institutions, and businesses to maintain, enhance, and restore ecological flows, species movement, and dynamic processes across intact and fragmented environments [23];

- "ecological network planning": an interconnected system of habitats whose biodiversity needs to be safeguarded. The geometry of the network has a structure based on the recognition of core areas, buffer zones and corridors that allow the exchange of individuals to reduce the extinction risk of local populations [14,23].

After the selection of key terms, we searched for the recurrences of them using a custom search (for instance, dates going from 1 January 1960 to 31 December 1970) on the 'Web of Science' search engine. The literature search was conducted divided into 6 time periods (decades): 1960-1970, 1971-1980, 1981-1990, 1991-2000, 2001-2010, 2011-2020. The methodological steps for our review are reported in the conceptual framework in Figure 1.

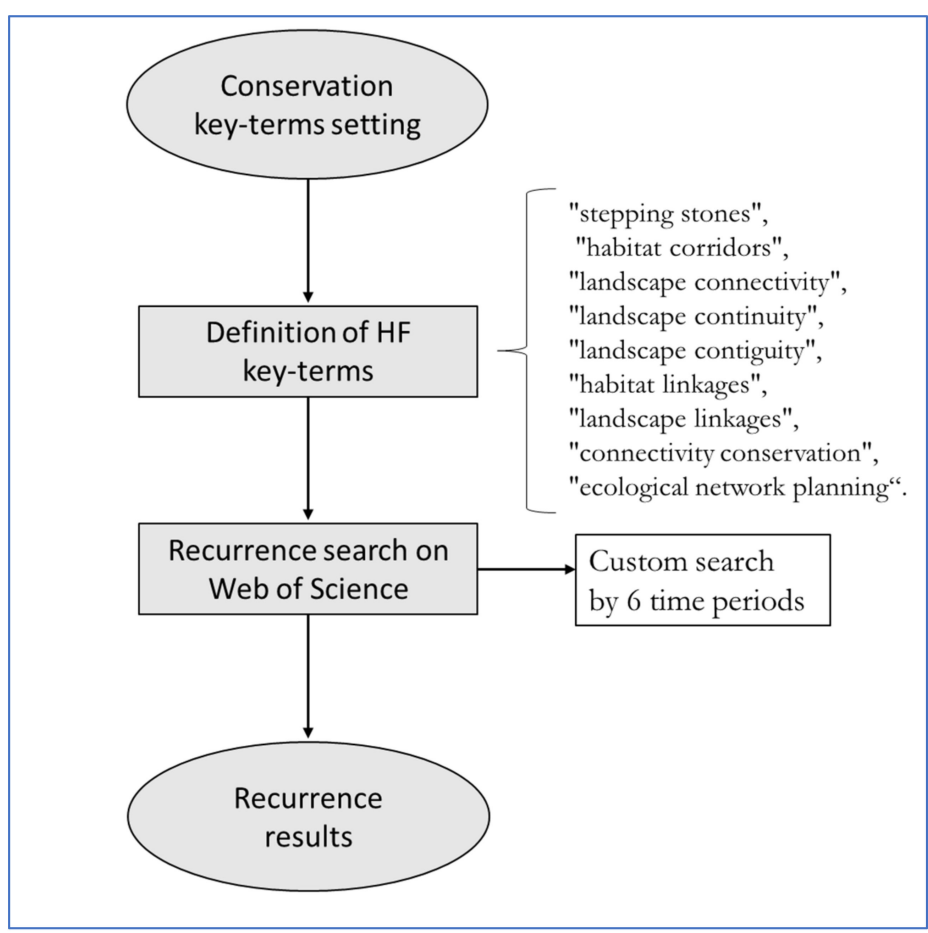

Figure 1. Conceptual framework reporting the methodological steps adopted in this review. 
To obtain data both on absolute and relative trends, for each key term, we calculated both the number of recurrences/decades and their frequency on the total of items. We graphically reported the temporal trends for decades, subdividing the most used key terms (named, focal terms) by the others (named, secondary terms).

We performed an $\chi^{2}$ test to compare the frequencies among decades and between key words, using the PAST software [25]. The alpha level was set at 0.05 .

\section{Results}

In total, we obtained 4029 recurrences on the Web of Science from 1981 to 2020 (no recurrence was obtained for the two decades from 1960 to 1980, see Table 1). The most used key terms (i.e., focal terms) were "stepping stones" ( $n=1833,45.5 \%)$, "habitat corridors" $(n=1656,41.1 \%)$, and "landscape connectivity" $(n=265,6.6 \%)$. The other key secondary terms ("landscape continuity", "landscape contiguity", "habitat linkages", "landscape linkages", "habitat linkages", “connectivity conservation", “ecological network planning") each showed a recurrence $<5 \%$.

Table 1. Recurrences of habitat fragmentation-related (focal and secondary) terms in Web of Science in the time range 1960-2020 ( $n$ : number of recurrences and fr: relative frequency).

\begin{tabular}{|c|c|c|c|c|c|c|c|c|c|c|c|c|c|c|c|c|c|c|}
\hline \multirow[b]{3}{*}{ Decades } & \multicolumn{6}{|c|}{ Focal Key Terms } & \multicolumn{12}{|c|}{ Secondary Key Terms } \\
\hline & \multicolumn{2}{|c|}{$\begin{array}{l}\text { Stepping } \\
\text { Stones }\end{array}$} & \multicolumn{2}{|c|}{$\begin{array}{l}\text { Habitat } \\
\text { Corridors }\end{array}$} & \multicolumn{2}{|c|}{$\begin{array}{l}\text { Landscape } \\
\text { Connectivity }\end{array}$} & \multicolumn{2}{|c|}{$\begin{array}{l}\text { Landscape } \\
\text { Continuity }\end{array}$} & \multicolumn{2}{|c|}{$\begin{array}{l}\text { Landscape } \\
\text { Contiguity }\end{array}$} & \multicolumn{2}{|c|}{$\begin{array}{l}\text { Habitat } \\
\text { Linkages }\end{array}$} & \multicolumn{2}{|c|}{$\begin{array}{l}\text { Landscape } \\
\text { Linkages }\end{array}$} & \multicolumn{2}{|c|}{$\begin{array}{l}\text { Connectivity } \\
\text { Conservation }\end{array}$} & \multicolumn{2}{|c|}{$\begin{array}{c}\text { Ecological } \\
\text { Network } \\
\text { Planning }\end{array}$} \\
\hline & $n$ & fr & $n$ & fr & $n$ & fr & $n$ & fr & $n$ & fr & $n$ & fr & $n$ & fr & $n$ & fr & $n$ & fr \\
\hline 1960-1970 & 0 & 0 & 0 & 0 & 0 & 0 & 0 & 0 & 0 & 0 & 0 & 0 & 0 & 0 & 0 & 0 & 0 & 0 \\
\hline 1971-1980 & 0 & 0 & 0 & 0 & 0 & 0 & 0 & 0 & 0 & 0 & 0 & 0 & 0 & 0 & 0 & 0 & 0 & 0 \\
\hline 1981-1990 & 17 & 0.010 & 1 & 0.004 & 0 & 0 & 0 & 0 & 0 & 0 & 0 & 0 & 0 & 0 & 0 & 0 & 0 & 0 \\
\hline $1991-2000$ & 128 & 0.077 & 31 & 0.117 & 38 & 0.021 & 2 & 0.1 & 1 & 0.333 & 4 & 0.05 & 20 & 0.270 & 0 & 0 & 0 & 0 \\
\hline 2001-2010 & 413 & 0.249 & 92 & 0.347 & 349 & 0.190 & 4 & 0.2 & 0 & 0 & 32 & 0.4 & 34 & 0.459 & 3 & 0.037 & 5 & 0.294 \\
\hline 2011-2020 & 1098 & 0.663 & 141 & 0.532 & 1446 & 0.789 & 14 & 0.7 & 2 & 0.667 & 44 & 0.55 & 20 & 0.270 & 78 & 0.963 & 12 & 0.706 \\
\hline Total & 1656 & & 265 & & 1833 & & 20 & & 3 & & 80 & & 74 & & 81 & & 17 & \\
\hline
\end{tabular}

Among the focal key terms, we observed a progressive increase in the use of "stepping stones", "habitat corridors", and "landscape connectivity" from 1981 to 2020, with the most marked trends recorded for "landscape connectivity" and for "stepping stones", with a significant increase in the last decade (2011-2020; respectively, $\chi^{2}=1313.6$, and $\chi^{2}=571.08$, both of them: $p<0.001$; Figure 2).

However, considering the frequency of use over the decades it emerges that, among the focal key terms, "stepping stones" was progressively less recurrent from 1980 to today $\left(\chi^{2}=70.81, p<0.001\right)$, "habitat corridors" was significantly more used in the 1990s $\left(\chi^{2}=53.995, p<0.001\right)$, and finally the higher increase was observed in "landscape connectivity" $\left(\chi^{2}=55.201, p<0.001\right.$; Figure 3$)$.

Differently from the focal terms, the secondary ones showed heterogeneous trends starting from the 1990s (Figure 4).

Except for "landscape linkage", which showed a progressive decline, all the other terms showed a progressive incremental trend. Among these, the concept of "connectivity conservation" showed the most markedly significant increase $\left(\chi^{2}=57.97, p<0.001\right)$, establishing itself as the most used in the last decade. Therefore, we observed a clear turnover, with the replacement of the concept of "landscape linkages", widely used in the 1990s, with that of "connectivity conservation". The concept of "ecological network planning", which appears in the early 2000s in the scientific literature, showed, however, a low frequency of recurrences in recent decades (Figure 5). 


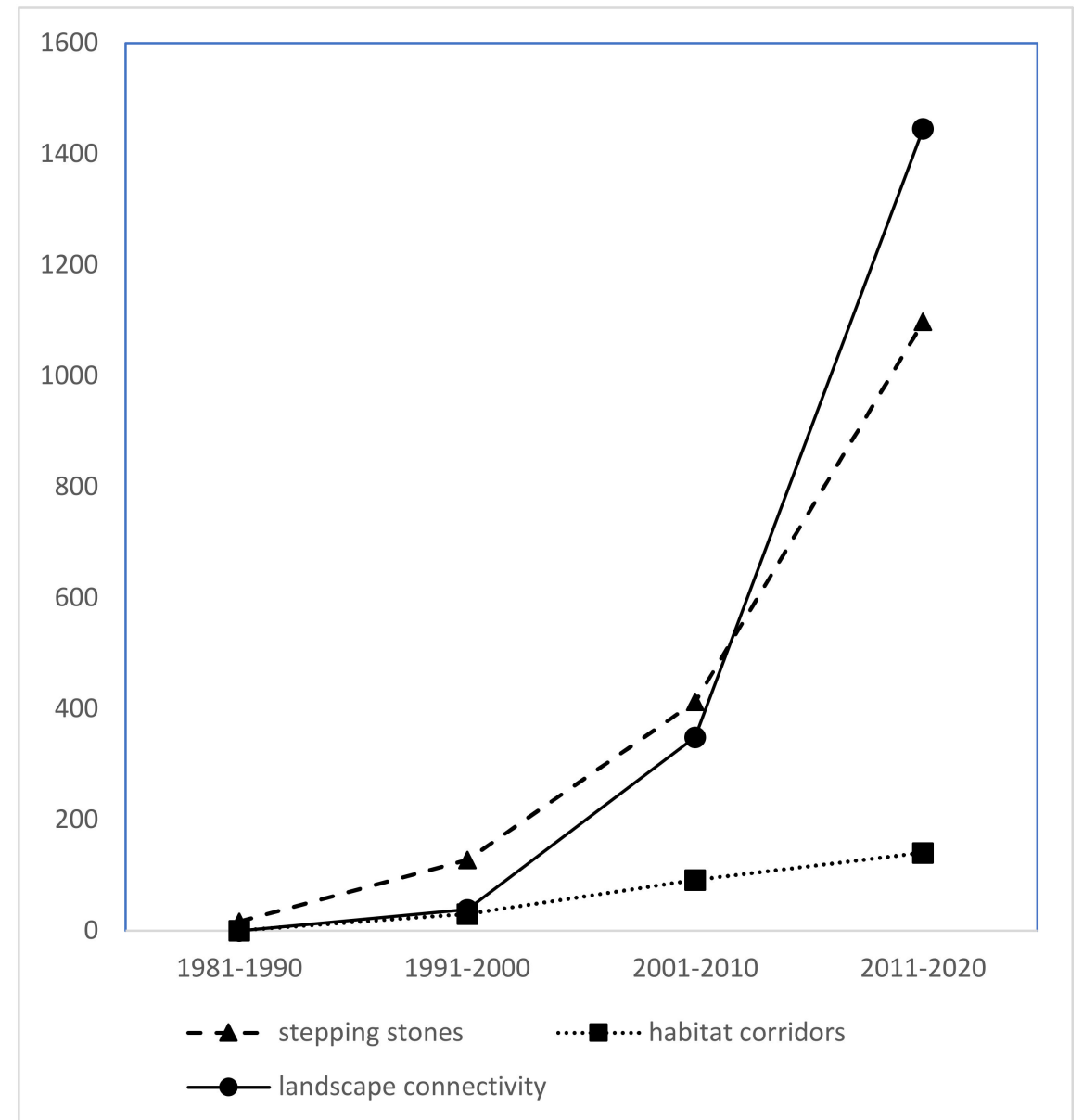

Figure 2. Key focal terms in the habitat fragmentation disciplinary arena. Trends in number of recurrences (y-axis) from 1981 to 2020.

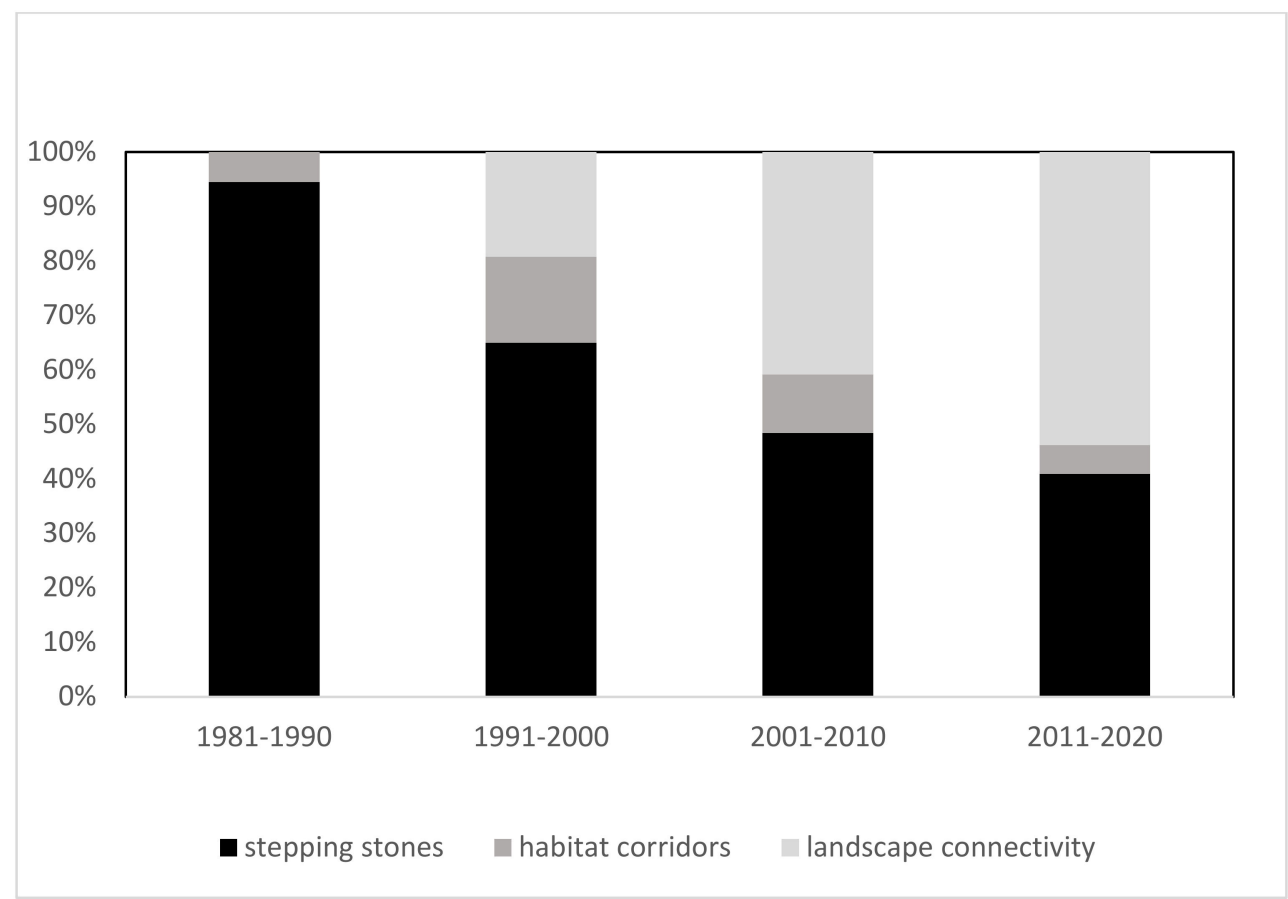

Figure 3. Percentage frequency of recurrence (y-axis) for the key focal terms from 1981 to 2020. 


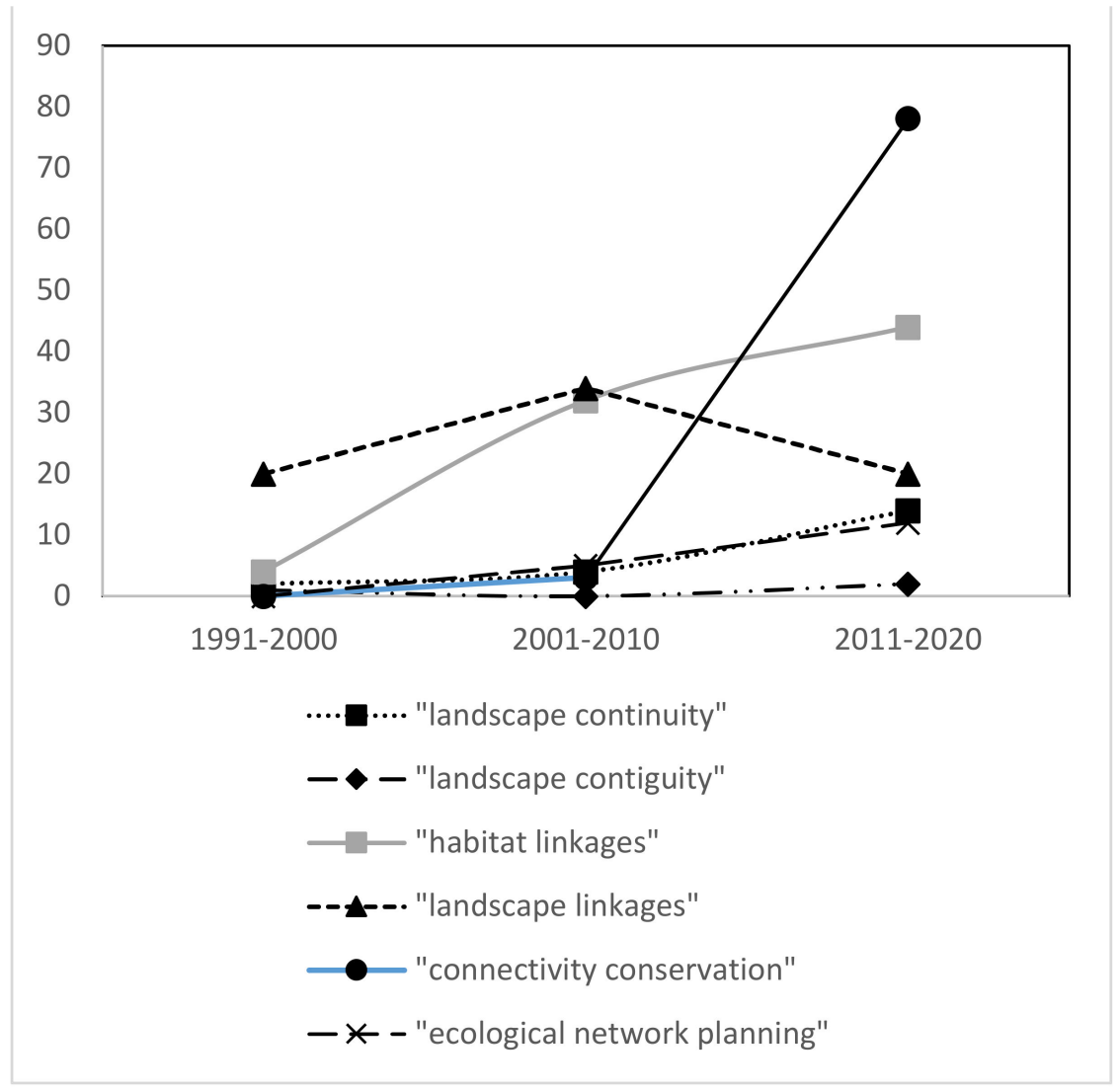

Figure 4. Secondary key terms in the habitat fragmentation disciplinary arena. Trends in number of recurrences (y-axis) from 1991 to 2020.

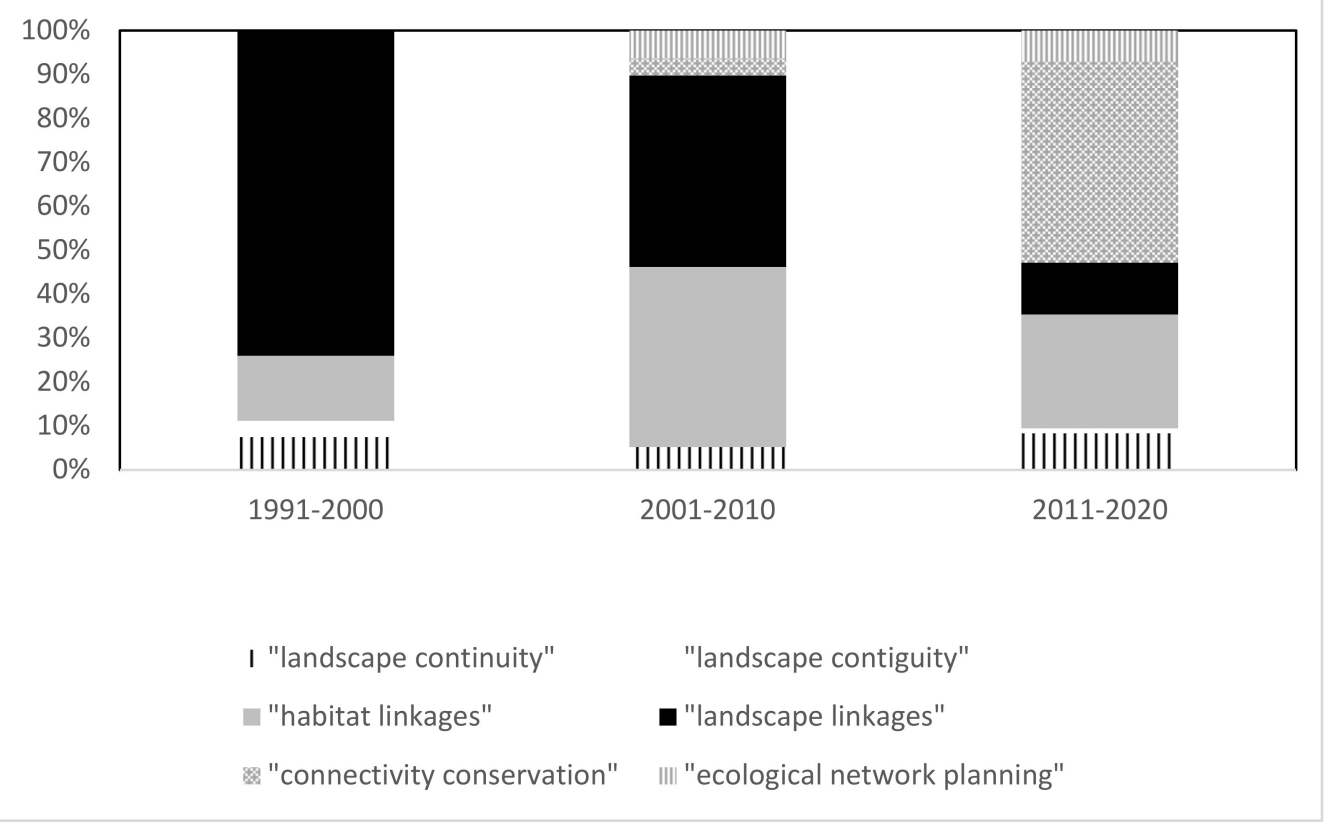

Figure 5. Percentage frequency of recurrence (y-axis) for the secondary focal terms from 1991 to 2020. 


\section{Discussion}

Although the key terms "corridors", "continuity", "contiguity" showed slight growth over the decades, we obtained evidence of progressively more marked use of the concept of "landscape connectivity" in the scientific literature. This last term (pertaining to the landscape scale) recently replaced other key concepts more effectively at a local scale (such as "stepping stones", "corridors") as a consequence of a change of perspective in conservation and landscape planning $[19,23]$. Indeed, in the 1990s, scientists and planners in the HF arena focused attention on the landscape scale where strategic ecological processes act, such as the metapopulation dynamics, reducing their effort at a local/patch scale [26]. All the actions of de-fragmentation (i.e., all the conservation measures aimed to promote the "landscape connectivity") also follow this trend (from local patterns to landscape processes; [27]). Therefore, the first hypothesis (i.e., that the use of the key concepts related to the larger landscape scale increase in recent years) was confirmed.

Regarding the key terms related to two main strategies contrasting the effects of HF on biodiversity, we observed that "connectivity conservation", a key term largely used in biological conservation [28], has been consolidated over the last decade both in an absolute and relative sense $[29,30]$, also with the advent of landscape ecology as a science [31,32].

Conversely, "ecological network planning", used in landscape and urban planning (e.g., [33]), showed a comparably lower recurrence. However, as hypothesized, we suppose that this gap in recurrences could be due to a bias in our research approach. Indeed, Web of Science is a search engine that looks for scientific research and does not intercept grey literature (e.g., ecological network plans and reports) drawn up by Public Agencies which rarely appears in indexed scientific journals. The logic of the two approaches (connectivity conservation projects vs. ecological network plans) is different, as highlighted by Boitani et al. [34]: while in the connectivity conservation the actions follow a project logic (with monitoring of the effectiveness of the actions, see [35]) and using indicators at the species level (as focal species, see [36-38]), in the ecological network planning, land planners focus their effort to design the use of the territory putting in mind the HF process, but they rarely provide for monitoring a plan's effectiveness $[39,40])$.

The defragmentation and connectivity strategies, designed to mitigate the effects of HF on ecosystems, might be implemented in real and complex socio-ecological contexts. These strategies could lead to conflicts between the needs of the human population (social and economic systems) and the need for conservation targets (i.e., ecological components). Therefore, they increasingly needed to be launched by mutual agreement with Public Agencies, stakeholders, land use planners and biological scientists [39,41]. This interdisciplinarity has led to the use of different terminology between disciplinary arenas. The need to integrate these two key terms therefore emerged when, operationally, actions in connectivity conservation and ecological network planning are carried out [42-48].

Our data show a progressively more marked use of the concept of connectivity in recent decades and the progressive abandonment of other concepts. Furthermore, they noted a progressive affirmation of connectivity conservation as an operational strategy on a landscape and regional scale designed to mitigate the effects of HF on species, communities, and ecosystems. Since semantic uncertainty generates barriers and misunderstandings with implications on operational actions [49], we believe that these indications may be useful to conservation biologists who should standardize their terminology. Furthermore, the transdisciplinary dialogue between conservation biologists and landscape planners should increase. Those who work on ecological network planning should use the terminology and logic adopted in connectivity conservation, as well as publish the evidence in scientific journals in order to reduce the transdisciplinary knowledge gap, already pointed out by [50].

However, our study shows some limitations. First, although Web of Science does not contain any relevant records on our selected targets, the issue of HF has been discussed by many pioneering studies using comparable terms (island biogeography applied to conservation, SLOSS-Single Large or Several Small debates for nature reserves [2,51-53]). Second, the search engine (i.e., Web of Science) showed limitations such as that not being 
able to intercept grey literature and papers without a DOI. Much of the grey literature in ecological network planning is not published (i) because the government agencies that do planning do not consider scientific publication as a project output (they publish reports and territorial plans), (ii) and because landscape planning actions do not follow the formal scientific approach (hypothesis testing), not monitoring the effectiveness in increasing connectivity by species (see [34]). This gap should be bridged by stimulating planners working in ecological networks (i) to put testable hypotheses in their plans through monitorable actions and (ii) to publish in scientific journals. Finally, regarding semantic ambiguity, our research did not investigate the semantic differences in the meaning attributed to each individual concept. For example, the concept of connectivity, in addition to its conceptual meaning, has also taken a quantitative meaning since the early decades of 2000, linked to its use as a quantitative index (for example in GIS analyses [54,55]). This aspect will deserve further study in the future.

Our survey aimed to define a general framework in the use of the different terminology over a very long period, without using specific variables at a single publication level and without a focus at a single species level or for different geographical areas. Therefore, further in-depth studies will be able to test whether the patterns of terminological use observed at a general level are the same for different biological groups and for different geographical contexts, also using multivariate approaches.

Author Contributions: Conceptualization, C.B.; methodology, C.B. and L.G.; software, L.G.; formal analysis, C.B., F.M.A. and M.S.; investigation, C.B. and L.G.; writing-original draft preparation, C.B. and L.G.; writing-review and editing, C.B., L.G., F.M.A. and M.S.; supervision, C.B. and F.M.A. All authors have read and agreed to the published version of the manuscript.

Funding: This research received no external funding.

Institutional Review Board Statement: Not applicable.

Informed Consent Statement: Not applicable.

Data Availability Statement: This review has been carried out analyzing data obtained by a number of publications publicy available from the Web of Science motor engine.

Acknowledgments: Three anonymous reviewers largely improved the first and the second draft of the manuscript. The Academic Editor provided further comments to the second draft.

Conflicts of Interest: The authors declare no conflict of interest.

\section{References}

1. William, L.; Thomas, J.R. Man's Role in Changing the Face of the Earth; Wenner-Gren Foundation and the National Science Foundation; The University of Chicago Press: Chicago, IL, USA, 1956.

2. Diamond, J.M. The island dilemma: Lessons of modern biogeographic studies for the design of natural reserves. Biol. Conserv. 1975, 7, 129-146. [CrossRef]

3. Soule, M.E. Conservation Biology: The Science of Scarcity and Diversity; Sinauer Associates: Sunderland, MA, USA, 1986.

4. Andrén, H.; Angelstam, P.; Lindström, E.; Widen, P. Differences in predation pressure in relation to habitat fragmentation: An experiment. Oikos 1985, 273-277. [CrossRef]

5. Wilcove, D.S.; McLellan, C.H.; Dobson, A.P. Habitat fragmentation in the temperate zone. Conserv. Biol. 1986, 6, 237-256.

6. Wilcox, B.A.; Murphy, D.D. Conservation strategy: The effects of fragmentation on extinction. Am. Nat. 1985, 125, 879-887. [CrossRef]

7. Quinn, J.F.; Harrison, S.P. Effects of habitat fragmentation and isolation on species richness: Evidence from biogeographic patterns. Oecologia 1988, 75, 132-140. [CrossRef]

8. Small, M.F.; Hunter, M.L. Forest fragmentation and avian nest predation in forested landscapes. Oecologia 1988, 76, 62-64. [CrossRef]

9. Klein, B.C. Effects of forest fragmentation on dung and carrion beetle communities in central Amazonia. Ecology 1989, 70, 1715-1725. [CrossRef]

10. Simberloff, D.; Cox, J. Consequences and costs of conservation corridors. Conserv. Biol. 1987, 1, 63-71. [CrossRef]

11. Noss, R.F. Corridors in real landscapes: A reply to Simberloff and Cox. Conserv. Biol 1987, 1, 159-164. [CrossRef]

12. Noss, R.F. Landscape connectivity: Different functions at different scales. In Landscape Linkages and Biodiversity; Hudson, W.E., Ed.; Island Press: Washington, DC, USA, 1991; pp. 27-39. 
13. Taylor, P.D.; Fahrig, L.; Henein, K.; Merriam, G. Connectivity is a vital element of landscape structure. Oikos 1993, 571-573. [CrossRef]

14. Kleyer, M.; Kaule, G.; Settele, J. Landscape fragmentation and landscape planning, with a focus on Germany. In Species Survival in Fragmented Landscapes; Settele, J., Margules, C., Poschlod, P., Henle, K., Eds.; Kluwer Academic Publishers: Dordrecht, The Netherlands, 1996; pp. 138-151.

15. Moore, J.D.; Krementz, D.G. Migratory connectivity of American Woodcock using band return data. J. Wildl. Manag. 2017, 81, 1063-1072. [CrossRef]

16. Metzger, J.P.; Décamps, H. The structural connectivity threshold: An hypothesis in conservation biology at the landscape scale. Acta Oecol. 1997, 18, 1-12. [CrossRef]

17. Bennett, A.F. Linkages in the Landscape. In The Role of Corridors and Connectivity in Wildlife Conservation, 2nd ed.; IUCN: Gland, Switzerland, 2003.

18. Bardwell, L.V. Problem-framing: A perspective on environmental problem-solving. Environ. Manag. 1991, 15, 603-612. [CrossRef]

19. Beier, P.; Noss, R.F. Do habitat corridors provide connectivity? Conserv. Biol. 1998, 12, 1241-1252. [CrossRef]

20. Githiru, M.; Lens, L. Application of fragmentation research to conservation planning for multiple stakeholders: An example from the Taita Hills, southeast Kenya. Biol. Conserv. 2007, 134, 271-278. [CrossRef]

21. Ferraz, K.M.P.M.D.B.; Morato, R.G.; Bovo, A.A.A.; da Costa, C.O.R.; Ribeiro, Y.G.G.; de Paula, R.C.; Jean Desbiez, A.L.; Angelieri, C.S.C.; Traylor-Holzer, K. Bridging the gap between researchers, conservation planners, and decision makers to improve species conservation decision-making. Conserv. Sci. Pract. 2021, 3, e330. [CrossRef]

22. Tischendorf, L.; Fahrig, L. How should we measure landscape connectivity? Landsc. Ecol. 2002, 15, 633-641. [CrossRef]

23. Battisti, C. Habitat fragmentation, fauna and ecological network planning: Toward a theoretical conceptual framework. Ital. J. Zool. 2003, 70, 241-247. [CrossRef]

24. Correa Ayram, C.A.; Mendoza, M.E.; Etter, A.; Salicrup, D.R.P. Habitat connectivity in biodiversity conservation: A review of recent studies and applications. Prog. Phys. Geogr. 2016, 40, 7-37. [CrossRef]

25. Hammer, Ø.; Harper, D.A.T.; Ryan, P.D. PAST-palaeontological statistics, ver. 1.89. Palaeontol. Electron. 2001, 4, 1-9.

26. Zeller, K.A.; Lewsion, R.; Fletcher, R.J.; Tulbure, M.G.; Jennings, M.K. Understanding the importance of dynamic landscape connectivity. Land 2020, 9, 303. [CrossRef]

27. Gurrutxaga, M.; Saura, S. Prioritizing highway defragmentation locations for restoring landscape connectivity. Environ. Conserv. 2014, 41, 157-164. [CrossRef]

28. Crooks, K.R.; Sanjayan, M.A. Connectivity conservation: Maintaining connections for nature. In Connectivity Conservation; Crooks, K.R., Sanjayan, M.A., Eds.; Cambridge University Press: Cambridge, UK, 2006; pp. 1-20.

29. Keeley, A.T.; Beier, P.; Creech, T.; Jones, K.; Jongman, R.H.; Stonecipher, G.; Tabor, G.M. Thirty years of connectivity conservation planning: An assessment of factors influencing plan implementation. Environ. Res. Lett. 2019, 14, 103001. [CrossRef]

30. Zhang, Z.; Meerow, S.; Newell, J.P.; Lindquist, M. Enhancing landscape connectivity through multifunctional green infrastructure corridor modeling and design. Urban For. Urban Green. 2019, 38, 305-317. [CrossRef]

31. Haila, Y. A conceptual genealogy of fragmentation research: From island biogeography to landscape ecology. Ecol. Appl. 2002, 12, 321-334.

32. Fischer, J.; Lindenmayer, D.B. Landscape modification and habitat fragmentation: A synthesis. Glob. Ecol. Biogeogr. 2007, 16, 265-280. [CrossRef]

33. Foltête, J.C. How ecological networks could benefit from landscape graphs: A response to the paper by Spartaco Gippoliti and Corrado Battisti. Land Use Policy 2019, 80, 391-394. [CrossRef]

34. Boitani, L.; Falcucci, A.; Maiorano, L.; Rondinini, C. Ecological networks as conceptual frameworks or operational tools in conservation. Conserv. Biol. 2007, 21, 1414-1422. [CrossRef]

35. Battisti, C. Unifying the trans-disciplinary arsenal of project management tools in a single logical framework: Further suggestion for IUCN project cycle development. J. Nat. Conserv. 2018, 41, 63-72. [CrossRef]

36. Bani, L.; Baietto, M.; Bottoni, L.; Massa, R. The use of focal species in designing a habitat network for a lowland area of Lombardy, Italy. Conserv. Biol. 2002, 16, 826-831. [CrossRef]

37. Amici, V.; Battisti, C. Selecting focal species in ecological network planning following an expert-based approach: A case study and a conceptual framework. Landsc. Res. 2009, 34, 545-561. [CrossRef]

38. Battisti, C.; Luiselli, L. Selecting focal species in ecological network planning following an expert-based approach: Italian reptiles as a case study. J. Nat. Conserv. 2011, 19, 126-130. [CrossRef]

39. Battisti, C. Ecological network planning-From paradigms to design and back: A cautionary note. J. Land Use Sci. 2013, 8, 215-223. [CrossRef]

40. Gippoliti, S.; Battisti, C. More cool than tool: Equivoques, conceptual traps and weaknesses of ecological networks in environmental planning and conservation. Land Use Policy 2017, 68, 686-691. [CrossRef]

41. Angelopoulos, N.V.; Cowx, I.G.; Buijse, A.D. Integrated planning framework for successful river restoration projects: Upscaling lessons learnt from European case studies. Environ. Sci. Pol. 2017, 76, 12-22. [CrossRef]

42. Scolozzi, R.; Geneletti, D. Assessing habitat connectivity for land-use planning: A method integrating landscape graphs and Delphi survey. J. Environ. Plan. Manag. 2012, 55, 813-830. [CrossRef] 
43. Treml, E.A.; Halpin, P.N. Marine population connectivity identifies ecological neighbors for conservation planning in the Coral Triangle. Conserv. Lett. 2012, 5, 441-449. [CrossRef]

44. Sahraoui, Y.; Leski, C.D.G.; Benot, M.L.; Revers, F.; Salles, D.; van Halder, I.; Barneix, M.; Carassou, L. Integrating ecological networks modelling in a participatory approach for assessing impacts of planning scenarios on landscape connectivity. Landsc. Urban Plan. 2021, 209, 104039. [CrossRef]

45. Pino, J.; Marull, J. Ecological networks: Are they enough for connectivity conservation? A case study in the Barcelona Metropolitan Region (NE Spain). Land Use Policy 2012, 29, 684-690. [CrossRef]

46. Shi, F.; Liu, S.; An, Y.; Sun, Y.; Zhao, S.; Liu, Y.; Li, M. Spatio-temporal dynamics of landscape connectivity and ecological network construction in Long Yangxia basin at the upper Yellow river. Land 2020, 9, 265. [CrossRef]

47. Wang, S.; Wu, M.; Hu, M.; Fan, C.; Wang, T.; Xia, B. Promoting landscape connectivity of highly urbanized area: An ecological network approach. Ecol. Indic. 2021, 125, 107487. [CrossRef]

48. Spinozzi, F.; Battisti, C.; Bologna, M.A. Habitat fragmentation sensitivity in mammals: A target selection for landscape planning comparing two different approaches (bibliographic review and expert based). Rend. Lincei 2012, 23, 365-373. [CrossRef]

49. Westgate, M.J.; Lindenmayer, D.B. The difficulties of systematic reviews. Conserv. Biol. 2017, 31, 1002-1007. [CrossRef] [PubMed]

50. Reyers, B.; Roux, D.J.; Cowling, R.M.; Ginsburg, A.E.; Nel, J.L.; Farrell, P.O. Conservation planning as a transdisciplinary process. Conserv. Biol. 2017, 24, 957-965. [CrossRef]

51. Whitcomb, R.F.; Lynch, J.F.; Opler, P.A.; Robbins, C.S. Island biogeography and conservation: Strategy and limitations. Science 1976, 193, 1027-1032. [CrossRef]

52. Wilson, E.O.; Willis, E.O. Applied biogeography. In Ecology and Evolution of Communities; Cody, M.L., Diamond, J.M., Eds.; Belknap Press of Harvard University: Cambridge, MA, USA, 1975; pp. 523-534.

53. Soule, M.E.; Wilcox, B.A.; Holtby, C. Benign neglect: A model of faunal collapse in the game reserves of East Africa. Biol. Conserv. 1979, 15, 259-272. [CrossRef]

54. Kindlmann, P.; Burel, F. Connectivity measures: A review. Landsc. Ecol. 2008, 23, 879-890. [CrossRef]

55. Pietsch, M. Contribution of connectivity metrics to the assessment of biodiversity-Some methodological considerations to improve landscape planning. Ecol. Indic. 2018, 94, 116-127. [CrossRef] 